\title{
SEROLOGICAL EVIDENCE OF BORRELIA BURGDORFERI INFECTION IN MEXICAN PATIENTS WITH FACIAL PALSY
}

\author{
Guadalupe Gordillo-PéreZ ${ }^{1}$, Ireri García-JuÁrez ${ }^{1}$, Fortino Solórzano-Santos ${ }^{2 *}$,

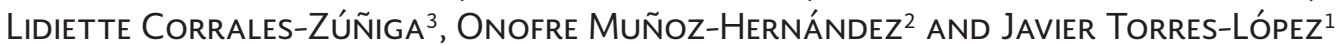

${ }^{1}$ Unidad de Investigación Médica de Enfermedades Infecciosas y Parasitarias (UIMEIP), Hospital de Pediatría, Centro Médico Nacional SXXI, Instituto Mexicano del Seguro Social, Mexico City; ${ }^{2 H o s p i t a l ~ I n f a n t i l ~ d e ~ M e ́ x i c o ~ " F e d e r i c o ~ G o ́ m e z " ~}$ Secretaría de Salud, Mexico City; ${ }^{3}$ Unidad de Medicina Física y Rehabilitación Villa Coapa, IMSS, Mexico City, Mexico

\begin{abstract}
Background: Facial palsy is the most frequent manifestation of neuroborreliosis in the United States, Europe, and Asia, whereas in Mexico, its frequency is unknown. Objective: We aimed to determine the frequency of Borrelia spp. infection in patients with acute facial palsy in Mexico. Materials and Methods: In this cross-sectional, referral hospital-based survey, 191 patients with facial palsy were selected and clinical and epidemiologic data recorded. IgM and IgG serum antibodies to Borrelia burgdorferi were tested by enzyme-linked immunosorbent assay (ELISA) and confirmed by Western-Blot (WB). IgM and IgG antibodies against the herpes viruses HSV-1, HSV-2, cytomegalovirus, and Epstein-Barr virus were tested by ELISA. Results: 71 patients (37\%) tested positive by ELISA to either Borrelia spp. or the herpes viruses. Of 25 patients (13\%) who tested positive for B. burgdorferi by ELISA, 23 (12\%) were confirmed by WB; 14 had IgM and 9 had IgG antibodies. Among the 14 IgM-WB positive patients, two cases recognized antigens of $B$. burgdorferi sensu stricto (s.s.), 10 of Borrelia garinii and 2 of B. afzelii, whereas all 9 IgG-WB positive were reactive against $B$. burgdorferi s.s. 14 patients had facial palsy in addition to other clinical data compatible with Lyme borreliosis. Patients infected with B. burgdorferi s.s. had a longer recovery time and a significantly higher risk (odds ratio $4.4,95 \%$ confidence interval 1.5-12.9) of recurrent facial palsy than patients infected with other Borrelia genospecies. Conclusions: Borrelia infection is frequent in facial palsy patients in Mexico, with B. burgdorferi s.s. and B. garinii being the most frequent causative species.
\end{abstract}

Key words: Facial palsy. Borrelia burgdorferi. Lyme borreliosis. Neuroborreliosis.

\section{INTRODUCTION}

Lyme borreliosis is classically caused by the spirochete Borrelia burgdorferi sensu lato (s.l.) and transmitted to humans by an infected tick bite (Ixodes spp). This disease is endemic in the United States, Europe, and in some Asian countries, and infection has spread from rural to urban zones. Its incidence in the United States increased over two-fold between 1991 and 2009 and has remained high, averaging around eight cases per 100,000 persons. B. burgdorferi sensu stricto (s.s.) is the predominant genospecies in the United States, whereas Borrelia afzelii and Borrelia garinii are more prevalent in Europe and $\mathrm{Asia}^{1-4}$. In Mexico, recent

\section{Corresponding author:}

*Fortino Solórzano-Santos

Hospital Infantil de México Federico Gómez

Dr. Márquez, 162

Col. Doctores, Del. Cuauhtémoc

C.P. 06720 , Ciudad de México, México

E-mail: solorzanof056@gmail.com 
reports have documented the presence of $B$. burgdorferi in the vector, the reservoir and in clinical cases, suggesting that Lyme disease is an emerging infection in our country ${ }^{5-10}$.

Lyme borreliosis has a broad range of clinical manifestations, affecting the skin, joints, heart, and musculoskeletal and nervous systems. Neuroborreliosis, acute facial nerve palsy, and meningitis are the most common manifestations in the disseminated stage of the disease. The reported frequency of facial palsy in Lyme disease is $25-50 \%$ in the United States and $65 \%$ in Europe; moreover, facial palsy is the sole clinical manifestation in about $20 \%$ of cases $^{11-15}$. The diagnosis of neuroborreliosis is complex since patients usually do not recall a tick bite or have previously noticed the diagnostic erythema migrans; the skin rash or neurological symptoms are nonspecific at presentation. The diagnosis of facial palsy secondary to Lyme borreliosis is even more difficult, and the etiology is generally suggested when serological studies are positive. Other infectious agents associated with facial palsy include the herpes viruses (Herpes simplex, Epstein-Barr virus [EBV], cytomegalovirus [CMV], and Varicella-Zoster) and to a lesser extent, other viruses such as adenovirus, HIV, influenza, rubella, and mumps virus ${ }^{15-17}$. In this study, we aimed to elucidate whether B. burgdorferi infection was associated with cases of facial palsy in patients treated in a general hospital in Mexico City.

\section{MATERIALS AND METHODS}

\section{Patients and serum samples}

A total of 830 consecutive patients with facial palsy, regardless of sex or age, were recruited in a cross-sectional survey at the rehabilitation hospital, a referral general hospital of the Social Security Institute in Mexico City, between April and December 2012. We excluded patients whose disease course was $\geq 8$ weeks (211), patients with diabetes (224), arterial hypertension (198), or neoplasia (6); we subsequently selected 191 patients with a clinical course lasting $\leq 8$ weeks. The study was approved by the ethical review board of the Rehabilitation Hospital. Informed consent was obtained from all patients. A blood sample was drawn from each patient at inclusion, and in cases with a clinical course $\leq 4$ weeks, a second sample was obtained 4 weeks later.

\section{Laboratory procedures}

Initial serodiagnosis for the detection of IgM and IgG antibodies against $B$. burgdorferi was performed using a commercial enzyme-linked immunosorbent assay (ELISA) (Enzygnost Borreliosis, Dade Behring, Marburg, Germany). Samples positive in the ELISA assay were tested by Western-Blot (WB), using whole-cell antigens from the three main species within the $B$. burgdorferi sensu lato complex, B. burgdorferi s.s., B. afzelii, and B. garinii (kindly supplied by Dr. B. Jaulhac, Strasbourg, France $)^{18}$. Samples were also tested using a commercial immunoblot assay for the detection of specific IgG antibodies against B. burgdorferi s.s. (MarDx Diagnostics, Carlsbad, CA). A case was defined as positive for B. burgdorferi s.s. if the IgM or IgG ELISA tests were positive and confirmed by a positive IgM-WB in which antibodies reacted with at least 2 of 3 protein bands (21-24, 39, and $41 \mathrm{kDa})$, or by a positive IgG-WB with antibodies against at least 5 of 10 protein bands $(18,21-24,28,30,39,41,45,58,66$, and $93 \mathrm{kDa}$ ). B. garinii infection was confirmed based on the EUCALB (the European Union Concerted Action on Lyme Borreliosis) criteria for WB, with positive IgG antibodies against protein $\mathrm{p} 17$, and against at least two other protein bands (p83/100, p58, p43, p39, p30, OspC, and p21). Similarly, B. afzelii infection was confirmed by WB with IgG antibodies against protein p14 and at least one additional protein (p83/100, p39, p30, OspC, or p21). Criteria for IgM-WB for B. afzelii are based on positive antibodies against at least one protein band ( $\mathrm{p39}$, OspC, p17, or p41), whereas $B$. garinii seropositivity requires antibodies against at least one protein band (p39, OspC, or p41) ${ }^{18-20}$.

Sera were also tested for specific IgM and IgG antibodies against Herpes simplex virus I and II, EBV, and CMV using commercial assays (ELISA Gull Kit, CMV or Quorum kit, USA).

\section{Statistical analysis}

Statistical analysis was performed with the Epi Info 3.2 program for descriptive statistics. Clinical differences between infected and uninfected patients were determined using Student's $t$-test, $\chi^{2}$, or Fisher's exact test, and odds ratio (OR) with $95 \%$ of confidence intervals $(\mathrm{Cl}) ; \mathrm{p}<0.05$ was considered statistically significant. 


\section{RESULTS}

A total of 191 patients were included into the study, with a mean age of $45 \pm 17$ years; 89 were male (46.5\%) and 102 were female (53.5\%). The mean duration of the facial palsy episode was 23.8 days $(95 \% \mathrm{Cl} 20-27.4)$. Unilateral facial palsy occurred in 188 cases $(98.4 \%)$, and only 3 had bilateral palsy; in addition, 37 (19.3\%) patients had recurrent episodes. Five patients $(2.6 \%)$ referred a recent tick bite and 103 (53.9\%) were exposed daily to potential tick carriers (dogs, cats, birds, and cows). Among the five patients who reported a recent tick bite, three patients developed Lyme borreliosis and two were negative for the disease.

\section{Serodiagnosis}

Seventy-one patients (37.1\%) were positive for B. burgdorferi or herpes virus infection by ELISA: $46(24 \%)$ were positive for IgM antibodies against the tested herpes viruses (HSV-1, HSV-2, CMV, and EBV), and 25 (13\%) for B. burgdorferi. 23 of the 25 B. burgdorferi cases (12\%) were confirmed by WB testing and were considered as true positives: 14 were positive for IgM and 9 for IgG antibodies (Table 1 ). Five of these 23 cases were negative in the first sample but seroconverted in the second sample, 3 cases for IgM and 2 for IgG. Among the 14 IgM-WB positive cases, two samples recognized antigens of $B$. burgdorferi s.s., 10 were positive for B. garinii, and two for B. afzelii. All 9 IgG-WB cases were reactive against $B$. burgdorferi s.s. antigens, with antibodies against the $41,58,45,66$, and $93 \mathrm{KDa}$ proteins (Table 1 ).

\section{Clinical characteristics}

The 14 patients positive for IgM by WB had a shorter disease course (mean: 20 days, $95 \% \mathrm{Cl} 5.40-34.60$ ) than those positive for IgG (mean 38 days, $95 \% \mathrm{Cl}$ 9.34-54.82) ( $p>0.05)$. Furthermore, four patients with a short clinical course (median: 13 days) had IgM antibodies recognizing low molecular weight proteins ( 23 or $18 \mathrm{KDa}$ ), whereas nine patients with a longer course (median: 55 days) had IgG antibodies against high molecular weight proteins (93 or $66 \mathrm{KDa})$.
In 10 of the 23 (44\%) cases positive by WB, facial palsy was the only clinical manifestation, whereas the remaining 14 patients presented additional manifestations (Table 2). Patients infected with $B$. burgdorferi had an increased risk of developing recurrent episodes of facial palsy than those not infected (OR $=4.4 ; 95 \%$ $\mathrm{Cl}$ 1.5-12.9; $\mathrm{p}<0.01$ ). In samples obtained during recurrent facial palsy episodes, IgG antibodies against B. burgdorferi were identified in nine patients and IgM was found in two cases.

About $71 \%$ of patients infected with Borrelia spp. were evaluated during the summer-autumn seasons, while noninfected cases of facial palsy were more evenly distributed throughout the year. All patients positive for B. burgdorferi were permanent residents of Mexico City, mainly from the city's central area. Only six patients had traveled in the 2 months prior to the symptoms development, to other areas of the country: Three patients had visited the Zacango zoo and La Marquesa park (state of Mexico), two had been at the Paricutín volcano park (state of Michoacán), and one had visited the state of Zacatecas. Patients infected with $B$. burgdorferi were treated with tetracycline for 14 days, and their mean time to recovery

Table 1 . Serology findings in 191 patients with facial palsy in Mexico City

\begin{tabular}{|c|c|c|c|c|}
\hline \multirow[t]{3}{*}{ Infectious agent } & \multirow{2}{*}{\multicolumn{2}{|c|}{$\frac{\text { Positive test }}{\text { ELISA }^{*}}$}} & \multirow{2}{*}{\multicolumn{2}{|c|}{$\begin{array}{c}\text { Positive test } \\
\text { Western Blot }\end{array}$}} \\
\hline & & & & \\
\hline & $\lg M$ & IgG & $\lg M$ & $\lg G$ \\
\hline $\begin{array}{l}\text { Borrelia burgdorferi sensu } \\
\text { stricto }\end{array}$ & 7 & 6 & 2 & 9 \\
\hline Borrelia garinii & 14 & 3 & 10 & 0 \\
\hline Borrelia afzelii & 4 & 3 & 2 & 0 \\
\hline Herpes simplex 1 & 15 & & & \\
\hline Herpes simplex 2 & 17 & & & \\
\hline Cytomegalovirus & 8 & & & \\
\hline Epstein-Barr virus & 6 & & & \\
\hline
\end{tabular}

* Six cases were positive for both IgG and IgM.

ELISA: Enzyme-linked immunosorbent assay

Table 2. Additional clinical characteristics in facial palsy patients infected with $B$. burgdorferi

\begin{tabular}{lc}
\hline Clinical characteristics & $\mathbf{N}=\mathbf{2 3}(\%)$ \\
\hline Recurrent facial palsy & $7(30)$ \\
Arthritis, arthralgia & $5(22)$ \\
Atrioventricular block & $1(4.3)$ \\
Erythema migrans & $1(4.3)$ \\
None & $9(39.1)$ \\
\hline
\end{tabular}

B. burgdorferi: Borrelia burgdorferi 
after antibiotic treatment was 4.6 weeks; in contrast, recovery in noninfected patients lasted a mean of 8.5 weeks $(p<0.05)$.

\section{DISCUSSION}

In this study, we determined that $36 \%$ of adult patients with idiopathic facial palsy had evidence of infection with the most common viral and bacterial agents, and $12 \%$ were specifically associated with $B$. burgdorferi. Although the frequency of facial palsy cases associated with Herpes simplex infection in this population was similar to that reported in other studies ${ }^{15-17}$, the frequency of those associated with $B$. burgdorferi was higher than that reported in the United States, but lower than that referred in Europe ${ }^{15,16,18}$. In previous reports studying the association of facial palsy with $B$. burgdorferi infection, differences in the infecting Borrelia genospecies have also been detected; in the United States, facial palsy is commonly caused by B. burgdorferi s.s., whereas in Europe, B. garinii and B. afzelii species have been frequently reported ${ }^{11-16,18}$. In our study, $50 \%$ of the cases were positive for B. burgdorferi and $50 \%$ for B. garinii or B. afzelii, a pattern similar to that reported in Europe. The serological response to $B$. afzelii and $B$. garinii suggests the possible participation of other Borrelia species in the etiology of Lyme neuroborreliosis in Mexican patients, which differs from cases in the United States. Of note, in Latin-American countries, only Brazil has reported the presence of $B$. garinii infection in patients who were farm workers and were exposed to ticks in rural areas $^{21}$.

About $50 \%$ of patients with facial palsy and Borrelia infection presented other clinical manifestations associated with Lyme Borreliosis, and about $25 \%$ developed recurrent facial palsy. These findings are in agreement with previous reports of Lyme neuroborreliosis in the United States, England, Denmark, and Sweden ${ }^{11-16,22}$.

In our study, most Borrelia associated cases occurred during the summer-autumn seasons, which differ with observations in other Northern countries, where cases occur mostly during the summer. These differences are probably influenced by climate variations and the associated occupational and recreational activities, which are important risk factors for exposure to the infected vector ${ }^{3,4,14,22-24}$.
Recovery after antibiotic treatment in Borrelia-infected patients was 4 weeks shorter than in infections caused by other agents, suggesting that an opportune diagnosis and appropriate treatment could decrease the recovery period; however, these results require confirmation in larger studies.

Some study limitations include the fact that it was conducted in a tertiary care hospital, which favors delayed patient referral as well as selection bias since not all facial palsy cases are referred to these hospitals. Antibodies were determined in blood samples but not in cerebrospinal fluid because in Mexico, this invasive procedure is not indicated in cases of facial palsy, as it is in other countries ${ }^{22}$. In regard to treatment, there is an important limitation because there is no consensus on when to begin antibiotic therapy, especially in cases with a prolonged clinical course ${ }^{22}$. In this study, all Borrelia-infected patients received antibiotic treatment and the time to facial palsy resolution was not established in infected cases that did not receive antibiotics. Therefore, a different study design is required to evaluate the benefit of antibiotics in this condition.

In conclusion, our study findings confirmed the presence of $B$. burgdorferi s.l. infection in about $12 \%$ of cases of facial palsy in Mexico City. The $B$. genospecies, B. afzelii, and B. garinii were detected in cases of disseminated neuroborreliosis suggesting an epidemiological pattern similar to that found in Europe rather than to the pattern found in the United States.

\section{ACKNOWLEDGMENTS}

The study was supported by Fondo para la Investigación en Salud, IMSS, Mexico, grants Prot/C2007/034 and CONACYT Salud 2008-C01-87868.

\section{REFERENCES}

1. Barbour AG, Fish D. The biological and social phenomenon of Lyme disease. Science. 1993;260:1610-6.

2. Centers for Diseases Control. Lyme Disease Data Tables, Reported Cases of Lyme Disease by State or Locality; 20052014. Available from: http://www.cdc.gov/lyme/stats/tables. html. [Last visited on 2016 Nov 19].

3. Steere AC. Lyme disease: A growing threat to urban populations. Proc Natl Acad Sci U S A. 1994;91:2378-83.

4. Shapiro ED. Borrelia burgdorferi (Lyme disease). Pediatr Rev. 2014:35:500-9. 
5. Gordillo-Pérez G, Vargas $M$, Solórzano-Santos $F$, Rivera A, Polaco O, Torres J. Demonstration of Borrelia burgdorferi infection in ticks of the Northeast zone of Mexico. Clin Microbiol Infect. 2009;15:496-8.

6. Gordillo-Pérez G, Torres J, Solórzano-Santos F, et al. Borrelia burgdorferi infection and cutaneous Lyme disease, Mexico. Emerg Infect Dis. 2007;13:1556-8.

7. Gordillo G, Solórzano-Santos F, Torres J, Velázquez E, García R, Vargas M. Epidemiological, clinical and zoonotic evidences for the existence of Lyme disease in Central Mexico. Int J Infect Dis. 2010;14S:76.018.

8. Gordillo G, Torres J, Solorzano F, Cedillo-Rivera R, Tapia-Conyer R, Muñoz O. Serologic evidences suggesting the presence of Borrelia burgdorferi infection in Mexico. Arch Med Res. 1999;30:64-8.

9. Gordillo-Pérez G, Torres J, Solórzano-Santos F, GarduñoBautista V, Tapia-Conyer R, Muñoz O. Estudio seroepidemiológico de Borreliosis de Lyme en la Ciudad de México y el Noreste de la República Mexicana. Salud Publica Mex. 2003;45: 351-5.

10. Gordillo-Pérez MG, Solórzano-Santos F. Enfermedad de Lyme. Experiencia en niños mexicanos. Bol Med Hosp Infant Mex. 2010;67:164-76.

11. Cooper L, Branagan-Harris M, Tuson R, Nduka C. Lyme disease and Bell's palsy: An epidemiological study of diagnosis and risk in England. Br J Gen Pract. 2017;67:e329-35.

12. Jonsson L, Stiernstedt G, Thomander L. Tick-borne Borrelia infection in patients with Bell's palsy. Arch Otolaryngol Head Neck Surg. 1987;113:303-6.

13. Halpering J], Golightly M. Lyme borreliosis in Bell's palsy. Neurology. 1992;42:1268-70.

14. Smouha EE, Coyle PK, Shukri S. Facial nerve palsy in Lyme disease: Evaluation of clinical diagnostic criteria. Am J Otol. 1997;18:257-61
15. Hohman MH, Hadlock TA. Etiology, diagnosis, and management of facial palsy: 2000 patients at a facial nerve center. Laryngoscope. 2014;124:E283-93.

16. Peitersen E. Bell's palsy: The spontaneous course of 2,500 peripheral facial nerve palsies of different etiologies. Acta Otolaryngol Suppl. 2002;549:4-30.

17. Murakami S, Mizobuchi $M$, Nakashiro $Y$, Doi $T$, Hato $N$ Yanagihara N. Bell palsy and herpes simplex virus: Identification of viral DNA in endoneurial fluid and muscle. Ann Intern Med. $1996 ; 124: 27-30$

18. Moore A, Nelson C, Molins C, Mead P, Schriefer M. Current guidelines, common clinical pitfalls, and future directions for laboratory diagnosis of Lyme disease, United States. Emerg Infect Dis. 2016;22.

19. Hauser U, Lehnert G, Wilske B. Validity of interpretation criteria for standardized Western blots (immunoblots) for serodiagnosis of Lyme borreliosis based on sera collected throughout Europe. J Clin Microbiol. 1999;37:2241-7.

20. Dressler F, Whalen JA, Reinhardt BN, Steere AC. Western blotting in the serodiagnosis of Lyme disease. J Infect Dis. 1993:167:392-400

21. Gonçalves DD, Moura RA, Nunes M, et al. Borrelia burgdorferi sensu lato in humans in a rural area of Paraná State, Brazil. Braz J Microbiol. 2015;46:571-5.

22. Bremell D, Hagberg L. Clinical characteristics and cerebrospinal fluid parameters in patients with peripheral facial palsy caused by Lyme neuroborreliosis compared with facial palsy of unknown origin (Bell's palsy). BMC Infect Dis. 2011;11:215.

23. Stanek G, Wormser GP, Gray J, Strle F. Lyme borreliosis. Lancet. 2012;379:461-73.

24. Illoldi-Rangel $P$, Rivaldi $C L$, Sissel B, et al. Species distribution models and ecological suitability analysis for potential tick vectors of Lyme disease in Mexico. J Trop Med. 2012;2012:959101. 